\title{
Using nonlinear models to define production, production rate, and precocity of strawberry cultivars
}

\author{
Maria Inês Diel ${ }^{1 *} \mathbb{D}$, Alessandro Dal'Col Lúcio ${ }^{1}$, Denise Schmidt ${ }^{2}$, Francieli de Lima Tartaglia ${ }^{1}$, \\ André Luis Tischler ${ }^{l}$, Darlei Michalski Lambrecht ${ }^{1}$
}

10.1590/0034-737X202269010008

\begin{abstract}
The aim of this study was to evaluate, using logistic model, the differences in early production, production rate and total productivity of two strawberry cultivars with transplants from different origins grown in substrate. The experiment was carried out in a randomized block design (RBD), with two strawberry cultivars (Albion and Camarosa) and two origins of transplants (National and Imported), with four repetitions consisting of eight plants. For the variable fruit mass, the logistic model was adjusted as a function of the accumulated thermal sum, and from the partial derivatives of the adjusted function, the critical points of the model were estimated. The use of the Logistic model allows evaluating precocity and rate of fruit production efficiently and accurately. The cultivar Camarosa was the most productive compared to the Albion cultivar, presenting a shorter production cycle, with a high production peak. The Albion cultivar was earlier, presenting more constant production during the evaluated production cycle. The transplant's origin did not show significantly different results for the cultivars evaluated. The producer must choose the cultivar that will be used based on its performance and also based on consumer preferences and fruit demand.
\end{abstract}

Keywords: Fragaria $\mathrm{x}$ ananassa; growth models; logistic; photoperiod; temperature.

\section{INTRODUCTION}

The strawberry (Fragaria $x$ ananassa Duch.) is a culture of widespread occurrence and high economic and social importance in various parts of the world. The main world producer in 2018 was China, followed by the United States, Mexico and Turkey. According to the Kist et al. (2019), Brazilian strawberry production reaches 120.000 tons, harvested from an area of 5278 hectares. The production and productivity of the crop have been growing every year, due to cultivars adapted to the most varied environments, and the implantation of new cultivation systems with high technology (Diel et al., 2018).

Strawberry cultivars available on the market are classified as being of short and neutral photoperiod. Those with short photoperiods are those that, as winter approaches in regions of the temperate and subtropical climate, the days become shorter and the temperatures cooler, stimulating flowering and fruiting. As temperatures rise and days lengthen, stolons start to emerge until the end of the reproductive period (Serçe \& Hancock, 2005; Durner, 2015). Neutral days cultivars are not influenced by the photoperiod, but depend exclusively on the temperature of the air and can flower continuously, the floral differentiation occurs when the daytime temperatures do not exceed $28^{\circ} \mathrm{C}$ (Guttridge, 1985; Serçe \& Hancock, 2005; Durner, 2015).

The choice of the cultivar to be implanted in the crop depends on the preferences of the producer to offer the fruit earlier to the consumer market and thereby add greater value to the product, or even, the interest in providing fruit all year round, with the possibility of a greater economic return in the months when there is little fruit supply. The choice of cultivars on neutral days allows the producer to offer the fruit on the market all year round if temperatures allow (Guttridge, 1985), but with lower productivity (Durner, 2018) short-day cultivars have a high

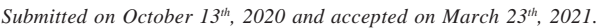

1' Universidade Federal de Santa Maria, Departamento de Fitotecnia, Santa Maria, Rio Grande do Sul, Brazil. mariaines.diel@hotmail.com; adlucio@ufsm.br; francielitartaglia@gmail.com; andreluistischler@gmail.com; darleilambrecht@yahoo.com

${ }^{2}$ Universidade Federal de Santa Maria, Departamento de Ciências Agronômicas e Ambientais, Frederico Westphalen, Rio Grande do Sul, Brazil. denise@ufsm.br

*Corresponding author: mariaines.diel@hotmail.com
} 
production peak between September and October, in addition to high flavor (Diel et al., 2018).

Among the short-day cultivars, the Camarosa cultivar, originally from the University of California - United States, has large fruits and early production, in addition to high flavor and aroma and high vigor of the plants (Bernardi et al., 2005). The development of the cultivar Camarosa is fast, with its phyllochron around $150^{\circ} \mathrm{C} \mathrm{day}^{-}$ ${ }^{1}$ and the beginning of the harvest around 80 days after transplantation (Diel et al., 2017). Of neutral days, the Albion cultivar, also originally from California, stands out, has constant production, not reaching very high production peaks, bright red color and high flavor (Bernardi et al., 2005). Its development is slower, requiring about $200{ }^{\circ} \mathrm{C}_{\text {day }}{ }^{-1}$ for leaf emission (Diel et al., 2017).

The precocity of strawberry cultivars are measured based on the number of days after transplanting the transplants that the plant took to start the reproductive period, as performed in Diel et al. (2017). However, this method does not seem to be very accurate because it is not possible to measure, in a simple way, the difference in production between cultivars or experimental treatments and the speed at which the maximum production rate is reached. The analysis of precocity, rate of production and total production become more accurate when they are determined from the modeling of total production. Nonlinear growth models can be used to extract as much information as possible from a data set. They provide the reality of the production cycle in each experimental treatment, allowing inferences and interpretations not obtained in analyzes of variances or complementary statistical tests such as comparisons of treatment averages or analyzes of linear regressions (Sari et al., 2018; Sari et al., 2019; Diel et al., 2020).

In addition to the photoperiod, the strawberry is regulated by temperature, and according to Paine et al. (2012), plants respond non-linearly to temperatures. In this way, regression models with sigmoidal responses are alternatives to assess non-asymmetric responses. Because of the above, this study aimed to evaluate, through logistic model, the differences in early production, production rate and total productivity of two strawberry cultivars with transplants from different origins grown on the substrate.

\section{MATERIALS AND METHODS}

\section{Plant material, site description, and experimental design}

The experiment was carried out at the Federal University of Santa Maria(27 $23^{\circ}$ S, 53 $3^{\circ} 25^{\prime} \mathrm{W}$ and $493 \mathrm{~m}$ of altitude), ), has climate classification of Cfa type, humid subtropical, showing characteristics of temperate rainy, and subtropical from the thermal point of view (Alvares et al., 2013).
The experiment was conducted inside galvanized steel greenhouses (semicircular), arranged in a north-south direction and measuring 20 -m length by 10 -m width with a 3.5-m height lateral post. Under 0.8-high wooden benches were placed white tubular plastic bags of $150-\mu \mathrm{m}$, where the strawberry seedlings were transplanted.

The irrigation and fertigation system was installed inside the bags and consisted of drip tubes. Nutrients were added together with irrigation water according to the formula and frequency of application developed by Gonçalves et al.,( 2016), adjusting according to the development of the culture.

For cultivation in substrate, $70 \%$ of burned rice husk and $30 \%$ of organic compost were used. The seedlings were transplanted after washing the substrate so that the electrical conductivity was not above $1 \mathrm{mS} \mathrm{cm}^{-1}$. The cultivars Albion (National) and Camarosa (National and Imported) were used, which were transplanted on May 26, 2015 and the imported Albion cultivar, transplanted on June 8, 2015. The transplants considered national were taken from a nursery in Agudo, located on the basaltic slope of Rio Grande do Sul, $\left(29^{\circ} 62\right.$ ' $\mathrm{S}, 53^{\circ} 22^{\text {' }}$ $\mathrm{W}, 83 \mathrm{~m}$ altitude). The imported transplants, grown in Argentina, were produced in a nursery called Patagonia Agrícola SA, located in El Maitén ( $42^{\circ} 3$ ' $\mathrm{S}, 71^{\circ} 10^{\prime} \mathrm{W}$, $720 \mathrm{~m}$ altitude).

A randomized block design with four replications was used, with eight plants in each experimental unit.

\section{Assessments Completed}

The air temperature inside the greenhouse was recorded with a portable digital thermohygrometer, with $0.1^{\circ} \mathrm{C}$ resolution (Th-02, 3B scientific) installed $1.5 \mathrm{~m}$ above the ground surface. The mean air temperature: $T_{\text {ave }}=\left(T_{\max }+T_{\text {min }}\right) / 2$, where $T_{\text {ave }}$ is the air average temperature; $T_{\max }$ is the maximum air temperature; $T_{\min }$ is the minimum air temperature.

The daily thermal sum $\left(\mathrm{TS}_{\mathrm{d}}\right)$ in ${ }^{\circ} \mathrm{C}$ day ${ }^{-1}$ was calculated by : $T S_{d}=T_{\text {ave }}-T_{b}$, where $\mathrm{TS}_{\mathrm{d}}$ is the daily thermal sum $\left({ }^{\circ} \mathrm{C}\right.$ day $\left.^{-1}\right) ; T_{\text {ave }}$ is the air average temperature; and $T_{b}$ is the base temperature (Arnold, 1960), considering the $T_{b}$ of $7^{\circ} \mathrm{C}$ (Mendonça et al., 2012). From this, we calculated the accumulated thermal sum $\left(\mathrm{TS}_{a}\right.$ in ${ }^{\circ} \mathrm{C}$ day $\left.^{-1}\right)$ up to the $i$ th day by: $T S_{a}=\sum_{\mathrm{i}=1}^{\mathrm{i}} T S_{d}$.

37 harvests were carried out throughout the production cycle (twice a week) during the complete maturity stage separating commercial from noncommercial fruits (fruits less than 6 grams were considered noncommercial). The commercial fruits harvested were weighed with the aid of a high precision scale (brand Bel, model SSR3000). The fruit mass per plant was calculated, dividing the total commercial mass of reaped fruits by the number of plants in the experimental units. 


\section{Adjustment of growth model}

In each experimental unit, the average mass of fruits per plant $\left(\mathrm{g} \mathrm{plant}^{-1}\right)$ obtained in each harvest was accumulated $(\mathrm{H} 1, \mathrm{H} 1+\mathrm{H} 2, \mathrm{H} 1+\mathrm{H} 2+\mathrm{H} 3, \ldots . \mathrm{H} 1+\mathrm{H} 2+\ldots \mathrm{H} 37)$, e Afterward, the logistic model was adjusted according to the following equation: $Y_{i}=\frac{\beta_{1}}{1+e^{\left(\beta_{1}-\beta_{2}-\beta_{3} x_{i}\right)}}+\varepsilon i$, where $Y_{i}$ is the mean mass of fruits per plant (dependent variable); $X_{i}$ is the accumulated thermal sum $\left(\mathrm{TS}_{\mathrm{a}}\right.$ ), in degree days, from the transplants transplant up to the $i$ th harvest (independent variable); $\hat{a}_{1}$ is the asymptotic value, and its values represent the total production of treatments; $\hat{a}_{2}$ is a parameter that reflects the distance between the initial value (observation) and the asymptote; $\hat{a}_{3}$ is the parameter that reflects the increment in fruit production rate.

The ordinary least squares method with a GaussNewton algorithm was used to obtain parameter estimates, using the $n l s$ () function in R software (R Core Team, 2021. Later, the coefficient of determination $\left(R^{2}\right)$ and the intrinsic $\left(c^{l}\right)$ and parametric $\left(c^{\theta}\right)$ nonlinearity were calculated by Bates \& Watts (1988). Afterward, $c^{i} x \sqrt{F(\alpha ; p, n-p)}$ and $c^{\theta} x \sqrt{F(\alpha ; p, n-p)}$ values were estimated, where $\mathrm{F}_{(\alpha, \mathrm{p}, \mathrm{n}-\mathrm{p})}=\mathrm{F}$ tabulated as a quantile of the $\mathrm{F}$ distribution in which $\alpha$ is 0.05 , $\mathrm{p}$ is the number of parameters in the model and $\mathrm{n}$ is the number of observations. Values under 0.3 and 1.0, respectively, are close to being unbiased. Shapiro-Wilk and Bartlett tests was used to test the normality and homogeneity of residuals, respectively.

The confidence intervals were obtained by a bootstrap approach, by the difference between the $97.5^{\text {th }}$ and $2.5^{\text {th }}$ percentiles of the bootstrap parameter estimates by the $n l s b o o t()$ function of the $n l s t o o l s$ package in software R (Baty et al., 2015). Differences between treatments were considered when the confidence intervals did not cross.

The coordinates of the critical points of the logistic model, maximum acceleration point (MAP), inflection point (PI), maximum deceleration point (MDP) and asymptotic deceleration point (ADP), were obtained according to the methodology described in (Mischan et al., 2011): inflection point (PI): $\frac{d^{2} y(x)}{d x^{2}}=0$; point of maximum acceleration (MAP) and point of maximum deceleration (MDP): $\frac{d^{3} y(x)}{d x^{3}}=0$; and point of asymptotic deceleration (ADP): $\frac{d^{4} y(x)}{d x^{4}}=0$. The precocity was defined when the PI was achieved (rate production of fruit was maximal). The concentration of production ( MAP MDP) corresponding to the time during which the production increased exponentially (Sari et al., 2018).

\section{RESULTS AND DISCUSSION}

The results of the estimated logistic model for the production of strawberry fruits were different in each evaluated cultivar. For all treatments, the intrinsic and parametric nonlinearity were less than 0.3 and 1.0 respectively (Table 1). For non-linear regression models, the quality of the fit must be defined from the results of the linearity measures proposed by Bates and Watts. The use of bootstrap confidence intervals (CI) to estimate the parameters circumvents the non-compliance with the assumptions of the regression models, normality, heterogeneity and autocorrelation of errors, and also allows comparisons to be made between the different treatments (Sari et al. 2019; Diel et al. 2020).

The modeling of the production mass of strawberry fruits in the function of the accumulated thermal sum was efficient with the use of the Logistic model since the culture of the strawberry is dependent on the temperature for its growth and development (Diel et al., 2017; Paine et al., 2012; Sønsteby et al., 2013; Sønsteby \& Heide, 2008).

From the confidence intervals of the parameters, it can be seen that the cultivar Camarosa, regardless of the origin of the transplants used, presented a greater asymptote $\left(\beta_{1}\right)$ proving to be the most productive (620 and 630 grams for Imported and National Camarosa respectively). The cultivar Albion presented the lowest estimates for the parameter $\beta_{1}$ when compared to cultivar Camarosa. Even though the CIs are not significant, it reached 573 and 592 grams for the Imported and National cultivars (Figure 1, $2 \mathrm{~A}$ and $2 \mathrm{~B}$ ).

The cultivars Albion and Camarosa have different photoperiodic responses. The cultivar Camarosa is of short days (sensitive to the photoperiod) while Albion is neutral days (indifferent to the photoperiod) (Hancock, 1999). This differentiation is important because on short days and low temperatures floral induction occurs, while fruiting occurs on long days and mild temperatures (Heide, 1977).

The production of strawberry fruits in cultivars with different photoperiodic responses may present differences in fruit yield and production. While the short-day cultivar is regulated by the photoperiod and temperature, production decreases over long days, whereas the cultivars of neutral days, which are indifferent to

Table 1: Values of intrinsic $\left(\mathrm{c}^{l}\right)$ and parametric $\left(\mathrm{c}^{\theta}\right)$ non-linearity for Albion and Camarosa cultivars from seedlings of national and imported origin

\begin{tabular}{lcc}
\hline Treatments & $\mathbf{c}^{\boldsymbol{I}}$ & $\mathbf{c}^{\boldsymbol{\theta}}$ \\
\hline Camarosa imported & 0.05 & 0.58 \\
Albion imported & 0.05 & 0.98 \\
Camarosa national & 0.05 & 0.65 \\
Albion national & 0.03 & 0.68 \\
\hline
\end{tabular}

Rev. Ceres, Viçosa, v. 69, n.1, p. 055-061, jan/feb, 2022 
photoperiodic variations and are regulated exclusively by temperature, can continue producing in long-day conditions when temperatures are not too high (Durner, 2015).

The results presented here reveal that there are no significant differences between the origin of imported and national strawberry transplants, contrary to what was observed by Oliveira \& Scivittaro (2009), who concluded that transplants imported from Chile performed better when compared to those produced in the south of Rio Grande do Sul. Diel et al. (2018), evaluating different mixtures of substrates, cultivars and transplants origin, found significant differences between transplants origin for the cultivar Camarosa, with plants of national origin having higher production compared to imported transplants. For the Albion cultivar, the same authors found no significant differences between the transplant's origins.

For parameter estimates $\beta_{2}$ it can be identified that the Albion cultivar showed earlier production when compared to Camarosa in the two transplants evaluated. This statement is based on the response with low values of this parameter, indicating greater fruit ripening at the beginning of the harvest, that is, the cultivar Camarosa showed greater growth at the beginning of the harvest (Figure 1). This fact may also be due to the photoperiodic response of the cultivar, since its precocity may be related to the initiation and floral differentiation in less time, as it does not present stimuli to the photoperiod, being regulated exclusively by temperature.

As previously defined, the Albion cultivar is indifferent to the photoperiod. The strawberry culture has floral initiation controlled by changes in in the environment (Sønsteby \& Heide, 2008). The fruit production rate, defined by the estimates of the parameter $\beta_{3}$, showed significant differences between the cultivars Albion and Camarosa, but not between the origin of the transplants in each cultivar (Figure 1). The results obtained for cultivar Camarosa show that it took more time to produce at the beginning of the cycle and remained less time producing compared to cultivar Albion. However, it produced more in a shorter period demonstrated by the high value of evaluating the cultivation of two strawberry cultivars on organic substrates determined that the Albion cultivar started harvesting the fruits significantly earlier than the Camarosa cultivar, observing differences of 5 and 14 days for national transplants and imported, respectively.

The point of maximum acceleration (MAP) showed significant differences between the transplant's origins for the cultivar Camarosa (Figure 1, 2E and 2F). The MAP

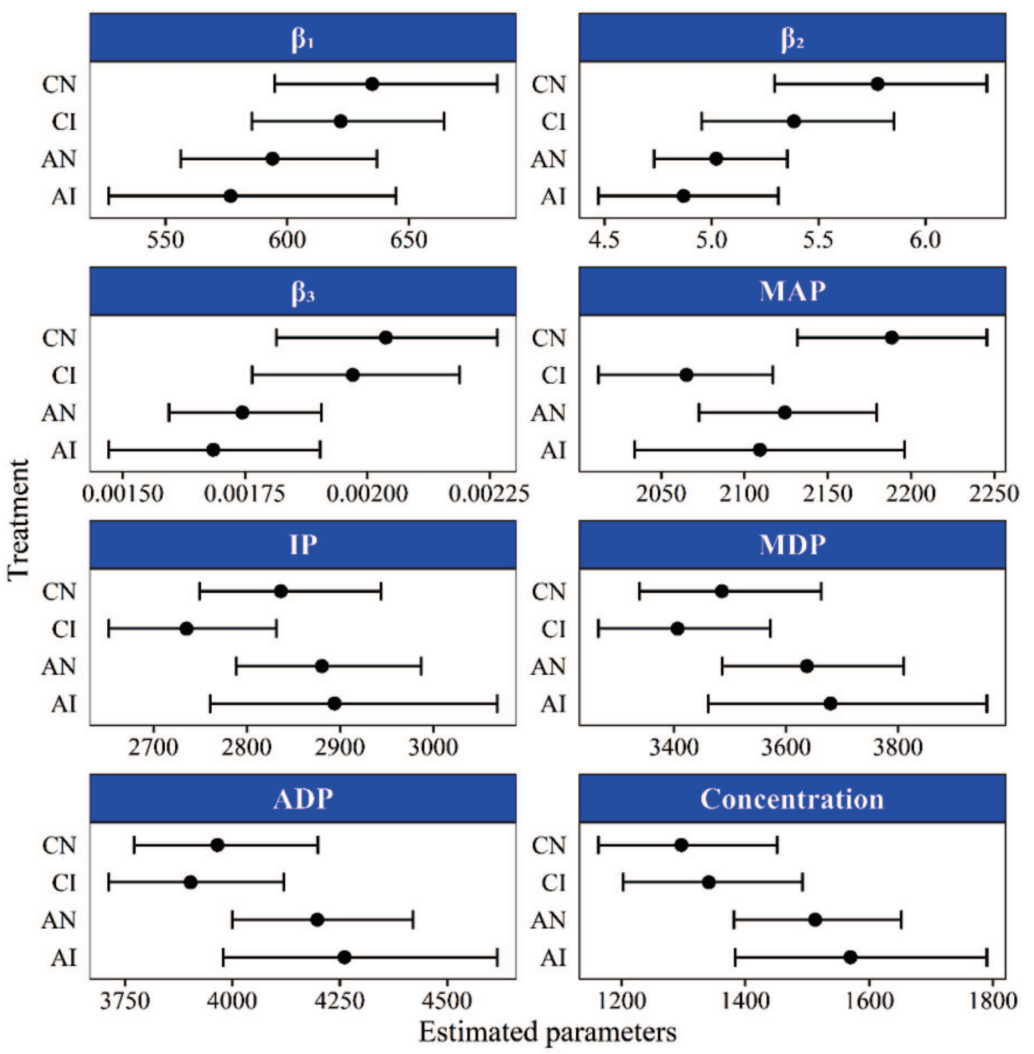

Figure 1: Confidence intervals for the parameters and critical points of the nonlinear logistic model estimated via bootstrap. $\beta_{1}$ (Asymptote), $\beta_{2}$ (Scale parameter), $\beta_{3}$ (Growth Rate), MAP (maximum acceleration point), PI (inflection point), MDP (maximum deceleration point), ADP (asymptotic deceleration point) and Concentration (MDP-MAP), for two strawberry cultivars from different transplants origins: AI (Albion Imported), NA (Albion National), CI (Camarosa Imported), CN (Camarosa National). 
shows the maximum increments in the production rate. The lower this value the increments were in a shorter period and, in this case, the cultivar Camarosa of Imported origin had a high production rate, quickly reaching maximum fruit production compared to the cultivar of National origin. This statement can be confirmed by the inflection point (PI) value, being lower than in other treatments and reaching the PI with $2075^{\circ} \mathrm{C} \mathrm{day}^{-1}$ (Figure $1,2 \mathrm{C}$ and 2D). The highest MAP value, given to the cultivar Camarosa of national origin, reveals that the maximum increase was later.

A)

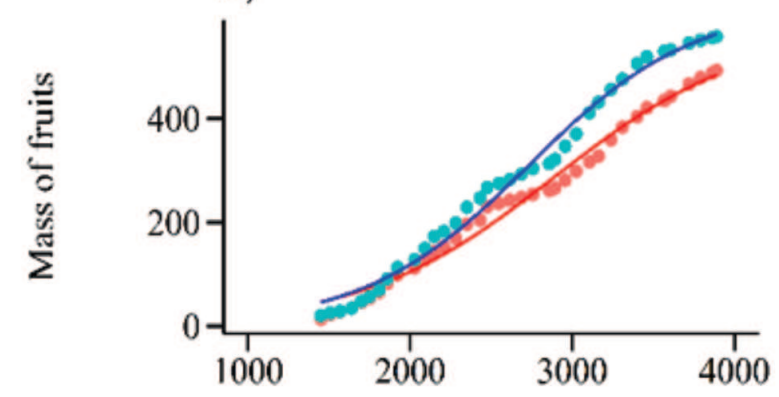

C)

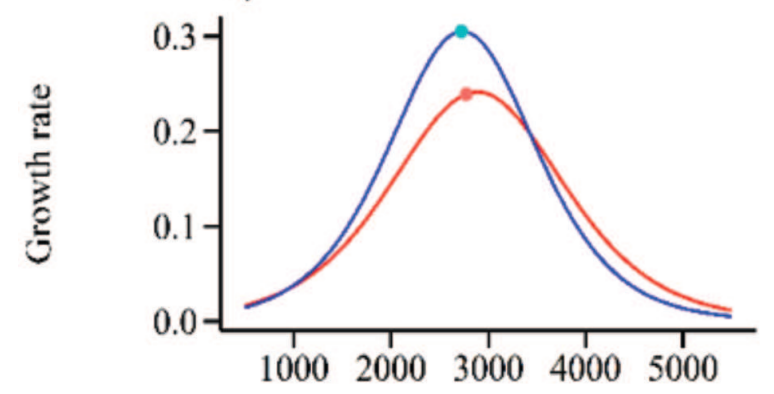

E)

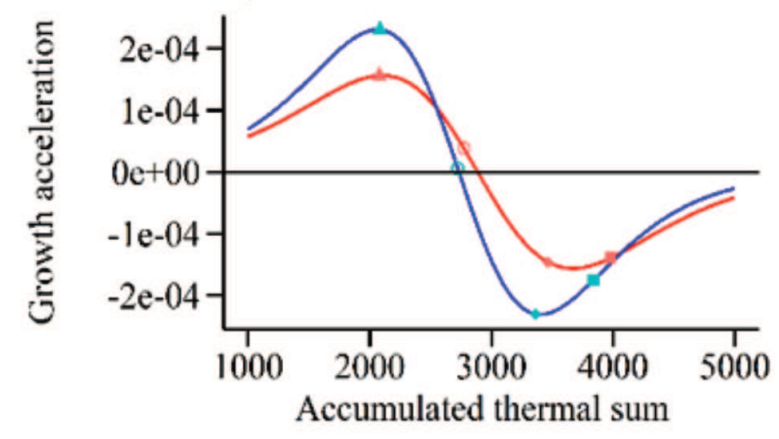

Critical points
These results can be interpreted thanks to the use of the non-linear Logistic regression model, which has critical points with biological interpretation. With the evaluation of only one variable, it is possible to obtain several relevant information for the production and for the decision making on which cultivar to choose according to the interests of the producer (Sari et al., 2018; Diel et al., 2019; Diel et al., 2020), whereas otherwise, this information would not be discovered.

When assessing the production of Capsicum chinense variety, Diel et al. (2020) adjusted a linear model and were

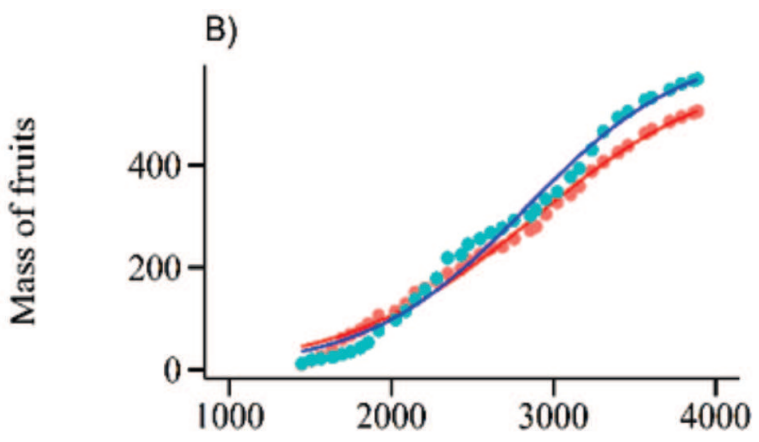

D)

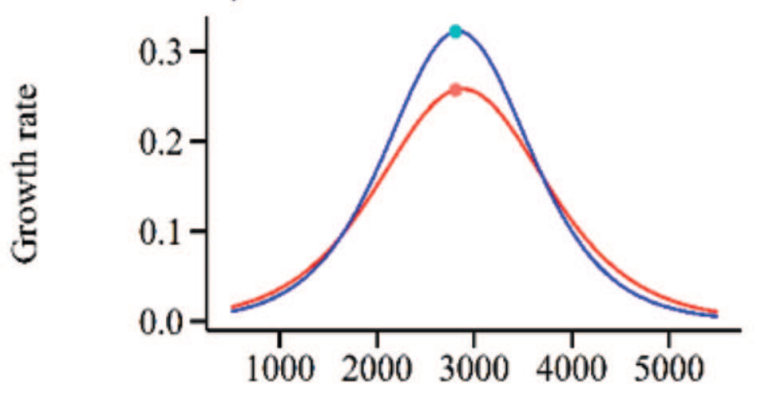

F)

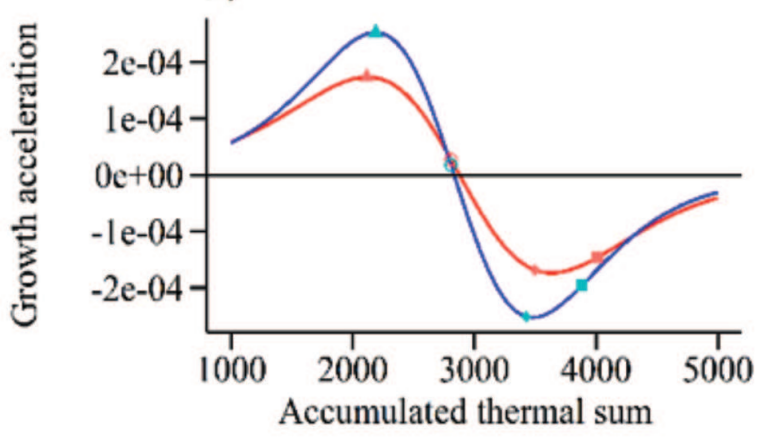

Observed values

Figure 2: Logistic model adjusted for fruit mass of the cultivars Albion and Camarosa of imported (A) and national (B) transplants; fruit production rate: (C) imported transplants and (D) national transplants; critical points of the adjusted model (PI: inflection point, MAP: maximum acceleration point, ADP: asymptotic deceleration point, MDP: maximum deceleration point): (E) for imported transplants $(\mathrm{F})$ national transplants. 
able to determine only which cultivar was more productive, but failed to show the productive response of the crop throughout the cycle, unlike when they adjusted the Logistic model, characterized the entire crop production cycle.

The inflection point (PI) is defined as the moment when the maximum rate of fruit production occurs. The PI showed differences for the cultivar Camarosa between the transplant's origins, with the Imported origin reaching the maximum production rate before the National Origin and the Albion cultivar reaching the maximum rate later (Figure 2C). Thus, it can be seen that the Albion cultivar, even having greater precocity concerning the Camarosa cultivar (lower), had a smaller increase in production during the cycle and took longer to reach the maximum fruit production rate, evidenced by the higher values of PI and MAP, that is, this cultivar remained to produce longer, even if the increments in production were smaller than those conferred to cultivar Camarosa. According to Sari et al. (2018), when the PI is reached on a smaller scale of accumulated thermal sum or time, production is earlier, even if it has not started to produce fruit before. The same authors indicate that higher MAP indicates a low degree of ripeness in the first harvests, that is, slower fruit maturation.

Regarding the maximum deceleration point (MDP) and the asymptotic deceleration point (ADP), it can be seen that the cultivar Camarosa decreased the production rates before the Albion cultivar (Figure 2), evidencing previous statements. There were no significant differences between the origins of transplants in each cultivar. With this concerning the concentration of harvests, determined by the difference in MDP and MAP, it is observed that the Albion cultivar had a longer production cycle when compared to the cultivar Camarosa (Figure 1, 2E and 2F). The cultivar Camarosa showed high production rates in less time, while the Albion cultivar produced less for a longer time, and in this way, the choice of cultivar is emphasized taking into account the interest of the producer.

The production of the cultivar Camarosa in a shorter period is because it is sensitive to variations in the photoperiod, that is when the days started to lengthen and temperatures increased, the emission of stolons started and the emission of flowers and consequently of fruits decreased. On the contrary, the Albion cultivar is insensitive to photoperiodic variations and has continuous flowering when the length of the day starts to lengthen, but it can decrease flowering if temperatures are high (Sønsteby \& Heide, 2008).

\section{CONCLUSIONS}

The logistic growth model, adjusted for strawberry fruit mass as a function of the accumulated thermal sum, explained the production cycle showing the main differences between cultivars.
The cultivar Camarosa was the most productive compared to the Albion cultivar, presenting a shorter production cycle, with a high production peak.

The Albion cultivar was earlier, presenting more constant production during the evaluated production cycle. The transplant's origin did not show significantly different results for the cultivars evaluated.

\section{ACKNOWLEDGEMENTS, FINANCIAL SUPPORT AND FULL DISCLOSURE}

We thank the Coordenação de Aperfeiçoamento de Pessoal de Nível Superior (CAPES) and Conselho Nacional de Desenvolvimento Científico e Tecnológico (CNPq) for granting the scholarships to the researchers.

\section{CONFLICT OF INTERESTS}

There is no conflict of interests in carrying the research and publishing the manuscript.

\section{REFERENCES}

Alvares CA, Stape JL, Sentelhas PC, De Moraes Gonçalves JL \& Sparovek G (2013) Koppen's climate classification map for Brazil. Meteorological Zeitschrift, 22:711-728.

Bates DM \& Watts DG (1988) Nonlinear Regression Analysis and its Applications. $2^{\text {nd }}$ ed. New York, Wiley. 392p.

Baty F, Ritz C, Charles S, Brutsche M, Flandrois JP \& DelignetteMuller ML (2015) A Toolbox for Nonlinear Regression in R/ : The Package nlstools. Journal of Statistical Software, 66:1-21.

Bernardi J, Hoffmann A, Antunes LEC \& Freire J de M (2005) Sistema de Produção de Morango para Mesa na Região da Serra Gaúcha e Encosta Superior do Nordeste. Available at: http:// sistemasdeproducao.cnptia.embrapa.br/ FontesHTML/Morango/MesaSerraGaucha/plantio.htm. Accessed on: January $15^{\text {th }}$, 2021 .

Diel MI, Lucio AD, Valera OVS, Sari BG, Olivoto T, Pinheiro MVM, Melo PJ, Tartaglia FL \& Schmidt D (2020) Production of biquinho pepper in different growing seasons characterized by the logistic model and its critical points. Ciência Rural, 50:e20190477.

Diel MI, Pinheiro MV, Cocco C, Thiesen LA, Altíssimo BS, Fontana DC, Caron BO \& Testa V (2017). Artificial vernalization in strawberry plants: phyllochron, production and quality. Australian Journal of Crop Scince, 11:1315-1319.

Diel MI, Pinheiro MVM, Cocco C, Fontana DC, Caron BO, de Paula GM, Pretto MM, Thiesen LA \& Schmidt D (2017) Phyllochron and phenology of strawberry cultivars from different origins cultivated in organic substracts. Scientia Horticulturae, 220:226-232.

Diel MI, Pinheiro MVM, Thiesen LA, Altíssimo BS, Holz E \& Schmidt D (2018) Cultivation of strawberry in substrate: Productivity and fruit quality are affected by the cultivar origin and substrates. Ciência e Agrotecnologia, 42:229-239.

Diel MI, Sari BG, Krysczun DK, Olivot T, Pinheiro MVM, Meira D, Schmidt D \& Lúcio AD (2019) Nonlinear regression for description of strawberry ( Fragaria $\mathrm{x}$ ananassa ) production. Journal Horticulture Science and Biotechnolgy, 94:259-273.

Durner EF (2015) Photoperiod affects floral ontogeny in strawberry (Fragariaxananassa Duch.) Scientia Horticulturae, 194:154-159. 
Durner EF (2018) Plug size and density during greenhouse conditioning do not affect late summer and early fall production of June-planted 'Albion' strawberry (Fragaria X ananassa Duch.) in the plasticulture system. Scientia Horticulturae, 240:268272 .

Gonçalves MA, Vignolo GK, Antunes LEC \& Reisser Junior C (2016) Produção de Morango Fora do Solo. Pelotas, Embrapa. $32 \mathrm{p}$

Guttridge CG (1985) Fragaria x ananassa. In: Halevy AH (Ed.) Handbook of Flowering. Boca Raton, CRC Press. p.16-33.

Hancock J (1999) Strawberries. $1^{\text {st }}$ ed. Wallingford, CABI Pub. $237 p$.

Heide OM (1977) Photoperiod and Temperature Interactions in Growth and Flowering of Strawberry. Physiologia Plantarum, 40:21-26.

Kist BB, dos Santos CE, de Carvalho C \& Beling RR (2019) Anuário Brasileiro de Horti \& Fruti. $1^{\text {st }}$ ed. Santa Cruz do Sul, Editora Gazeta Santa Cruz. 96p.

Mendonça HFC, Calvete EO, Nienow AA, Costa RC da, Zerbielli L \& Bonafé M (2012) Phyllochron estimation in intercropped strawberry and monocrop systems in a protected environment. Revista Brasileira de Fruticultura, 34:15-23.

Mischan MM, Pinho SZ \& Carvalho LR (2011) Determination of a point sufficiently close to the asymptote in nonlinear growth functions. Scientia Agricola, 68:109-114.

Oliveira RP \& Scivittaro WB (2009) Produção de frutos de morango em função de diferentes períodos de vernalização das mudas. Horticultura Brasileira, 27:91-95.
Paine CET, Marthews TR, Vogt DR, Purves D, Rees M, Hector A \& Turnbull LA (2012) How to fit nonlinear plant growth models and calculate growth rates: An update for ecologists. Methods Ecology and Evolution, 3:245-256.

$\mathrm{R}$ development core team (2021) A language and environment for statistical computing. Vienna, R Foundation for Statistical Computing. Available at: https://www.R-project.org/. Accessed on: January $15^{\text {th }}, 2021$.

Rosa HT, Walter LC, Streck NA, Andriolo JL, Silva MR da \& Langner JA (2011) Base temperature for leaf appearance and phyllochron of selected strawberry cultivars in a subtropical environment. Bragantia, 70:939-945.

Sari BG, Lúcio AD, Souza Santana C, Olivoto T, Diel MI \& Krysczun DK (2019) Nonlinear growth models: An alternative to ANOVA in tomato trials evaluation. European Journal of Agronomy, $104: 21-36$

Sari BG, Olivoto T, Diel MI, Krysczun DK \& Lúcio AD (2018) Nonlinear modeling for analyzing data from multiple harvest crops. Agronomy Journal, 110:1-12.

Serçe S \& Hancock JF (2005) The temperature and photoperiod regulation of flowering and runnering in the strawberries, Fragaria chiloensis, F. virginiana, and F. x ananassa. Scientia Horticulturae, 103:167-177.

Sønsteby A \& Heide OM (2008) Temperature responses, flowering and fruit yield of the June-bearing strawberry cultivars Florence, Frida and Korona. Scientia Horticulturae, 119:49-54.

Sønsteby A, Opstad N \& Heide OM (2013) Environmental manipulation for establishing high yield potential of strawberry forcing plants. Scientia Horticulturae, 57:65-73. 